\title{
Usefulness of the Thyrotropin-Releasing Hormone Test in Pre-Clinical Acromegaly
}

\author{
Kazunori Kageyama, Takako Moriyama, Satoru Sakihara, Shinobu Takayasu, \\ TAKeshi Nigawara and ToshiHIRo SudA \\ Department of Endocrinology, Metabolism and Infectious Diseases, Hirosaki \\ University School of Medicine, Hirosaki, Japan
}

\begin{abstract}
Kageyama, K., Moriyama, T., Sakihara, S., Takayasu, S., Nigawara, T. and Suda, T. Usefulness of the Thyrotropin-Releasing Hormone Test in Pre-Clinical Acromegaly. Tohoku J. Exp. Med., 2005, 206 (4), 291-297 — Acromegaly is caused primarily by pituitary growth hormone $(\mathrm{GH})$-secreting tumors. It is usually recognized because of characteristic manifestations, and diagnosed clinically. However, there exists a mild stage of acromegaly, which poses a diagnostic problem due to the absence of typical clinical manifestations. Here we present four patients with pre-clinical acromegaly, who showed minimal acromegaloid features with elevated levels of insulin-like growth factor-I. Basal GH levels were within normal levels in 3 of 4 cases, while insulin-like growth factor-I levels were elevated above normal in all cases. Plasma GH levels were elevated in response to thyrotropin-releasing hormone (TRH) in all cases, indicating a diagnostic value of the TRH stimulation test. In contrast, an oral glucose tolerance test was not useful for the diagnosis, because of the low GH levels (less than $1 \mathrm{ng} / \mathrm{ml}$ ) and/or secondary to diabetes mellitus. In response to a dopamine agonist, GH levels were increased in the two cases, whereas GH levels were decreased or remained unchanged in the other two cases. We therefore suggest that the TRH stimulation test would be helpful to examine the presence of pre-clinical acromegaly. Diagnosis of the early stages of acromegaly is important to prevent progression to overt acromegaly. —— growth hormone; acromegaly; insulinlike growth factor-I; pituitary tumor (C) 2005 Tohoku University Medical Press
\end{abstract}

Acromegaly is caused primarily by pituitary growth hormone $(\mathrm{GH})$-secreting tumors. It is usually recognized because of characteristic manifestations with enlargement of the facial features, hands, and feet. The diagnostic criteria for acromegaly are still being discussed. While the clinical criteria are clear, the debate over the biochemical diagnosis is present in the literature (Dimaraki et al. 2002; Giustina and Melmed 2003). Moreover, a mild stage of acromegaly, which is not diagnosed by the present criteria, is known (Dimaraki et al. 2002; Trainer 2002). Plasma GH levels are generally elevated above normal, but not in all cases of acromegaly (Mims and Bethune 1974; Brockmeier et al. 1992). Thyrotropinreleasing hormone (TRH) stimulation test, oral glucose tolerance test (OGTT) and insulin-like growth factor (IGF)-I levels are helpful for the diagnosis of acromegaly. TRH-induced GH release would be caused by the abnormal induction or

Received March 23, 2005; revision accepted for publication May 10, 2005.

Correspondence: Kazunori Kageyama, M.D., The Third Department of Internal Medicine, Hirosaki University

School of Medicine, 5 Zaifu-cho, Hirosaki 036-8562, Japan.

e-mail: kkageyama@hkg.odn.ne.jp 
sensitization of TRH receptors on pituitary somatotroph adenoma cells (Harvey 1990), and plasma $\mathrm{GH}$ levels are elevated in response to TRH in 70-80\% of acromegaly (Irie and Tsushima 1972; Hanew et al. 1980). The plasma GH levels are examined by an OGTT, and acromegaly is diagnosed as a failure of decrease in plasma $\mathrm{GH}$ level to the normal level after an OGTT (Stewart et al. 1989). A single random measurement of the GH level would not be useful for the diagnosis or for excluding acromegaly, because a normal value may be a nadir level in an acromegalic patient; conversely, a high value may be a peak value in a normal individual (Thorner et al. 1998; Dimaraki et al. 2002). Measurement of GH levels every 10 min over $24 \mathrm{~h}$, therefore, is more accurate, but is prohibitive except for research purposes. The serum IGF-I level would be a better reliable indicator for screening of acromegaly, because it reflects overall GH secretion during the previous $24 \mathrm{~h}$ (Thorner et al. 1998). However, the normal range for serum IGF-I levels varies with age and gender, and should be corrected for them (Turgut et al. 2003). Furthermore, IGF-I level also reflects the liver function and the nutrition status. Therefore, the diagnosis could be wrong if only the GH- and IGF-I-based criteria are used.

We report here four patients with minimal acromegaloid features and elevated IGF-I levels. We define these patients as pre-clinical acromegaly by their features and by their response to the TRH test, which may be a useful tool in diagnosing pre-clinical acromegaly.

\section{Patients and Methods}

Patients

Four patients with minimal acromegaloid features were followed in our clinic, three women and one man, with only a mild thickening of the lips, increased spaces between teeth, slight broadening of the nose, or evaluated for slight prominence of the zygoma. Plasma GH and serum IGF-I levels were measured for the presence of pre-clinical or mild acromegaly. In these four cases, the IGF-I levels, adjusted by age- and gender-matched controls, were two fold higher than the level of the upper normal range. In order to further evaluate these patients, plasma GH levels in response to TRH, OGTT, and bromocriptine, a dopamine agonist, were examined to evaluate $\mathrm{GH}$ secretory dynamics.

Informed consent for the studies and the photos was obtained from the patients. All tests were performed according to clinical guidelines.

Assays

Plasma GH levels were measured by an immunoradiometric assay (IRMA) with a sensitivity of $0.3 \mathrm{ng} / \mathrm{ml}$ (Eiken Chemical Co., Tokyo). Serum IGF-I levels were measured by an IRMA (Daiichi Radioisotope Labs., Tokyo).

\section{Results}

\section{Patient characteristics}

The characteristics of the four patients are shown in Tables 1 and 2. None of the patients complained of visual field defects, galactorrhea, impotence, headache, or acral enlargement. In all four cases, facies were not typically acromegalic, i.e., with deep nasolabial furrows or prominent supraorbital ridges, but only with a mild thickening of the lips, increased spaces between teeth, or slight broadening of the nose (Fig. 1). In 3 of 4

TABLE 1. Clinical and laboratory features

\begin{tabular}{cccccc}
\hline Case & Age & M/F & GH $(\mathrm{ng} / \mathrm{ml})$ & IGF-I $(\mathrm{ng} / \mathrm{ml})$ & Pituitary tumor \\
\hline 1 & 65 & F & 1.2 & 289 & + \\
2 & 61 & F & 5.4 & 395 & - \\
3 & 72 & F & 0.6 & 340 & - \\
4 & 58 & M & 0.6 & 310 & + \\
\hline
\end{tabular}

Normal IGF-I ranges: cases 1 and 2, 37-150 ng/ml; case 3, 38-207 ng/ml; case 3, $59-215 \mathrm{ng} / \mathrm{ml}$. 


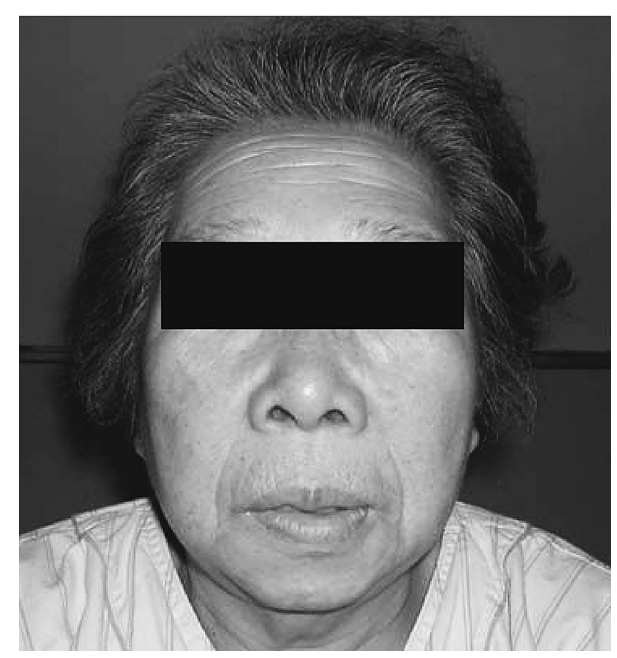

Case 1

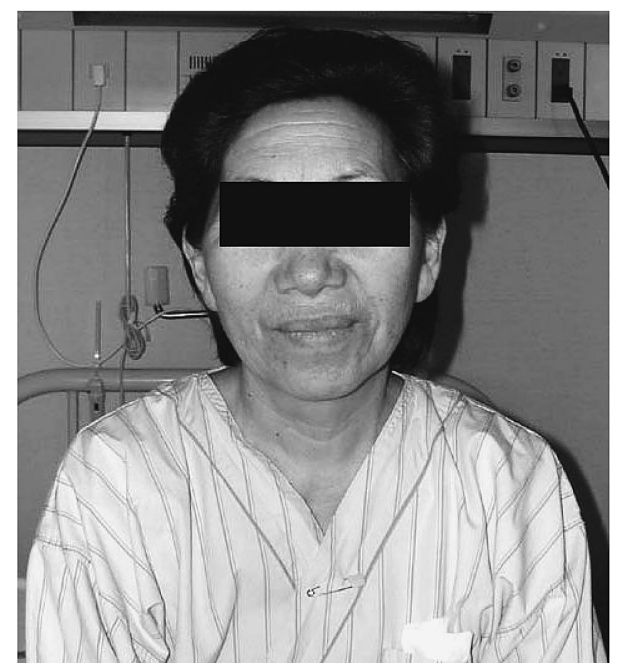

Case 2

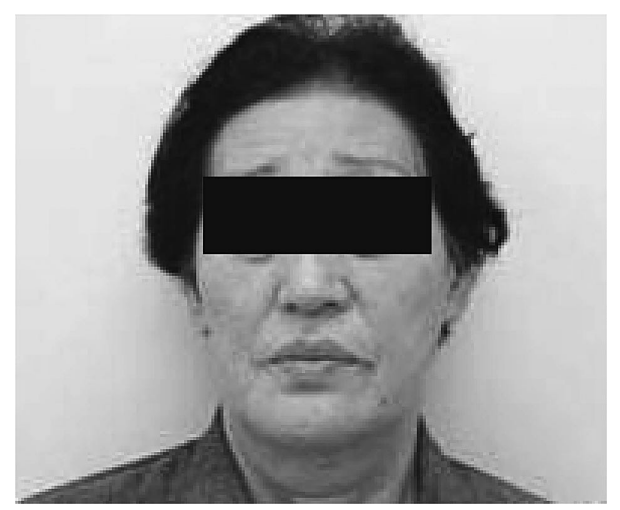

Case 3

Fig. 1. Absence of clinically acromegalic features in 3 cases (case 4 not available). cases, basal plasma GH levels were less than 1 $\mathrm{ng} / \mathrm{ml}$, while serum IGF-I levels were elevated above the normal range for each patient, compared with age- and gender-adjusted normal ranges (Table 1). Pituitary tumors were demonstrated by magnetic resonance imaging in the two cases. Hypertension and diabetes mellitus were not detected except in case 1.

\section{GH response to TRH}

The administration of TRH stimulates GH levels in acromegalic patients (Irie and Tsushima 1972; Hanew et al. 1980). The effects of TRH on GH levels were, therefore, examined in these patients. A significant response of $\mathrm{GH}$ level was set at a more than two-fold increase, compared with the basal level. As shown in Fig. 2, in all cases, plasma GH levels were increased in response to the intravenous administration of $200 \mu \mathrm{g}$, a dose for this loading study in Japan, of TRH (Fig. 2a), although pathophysiological conditions such as depression and liver cirrhosis were ruled out in the patients.

\section{$G H$ response to oral glucose tolerance test}

The criterion for a normal GH response to OGTT is less than $1 \mathrm{mg} / \mathrm{l}$ by using an IRMA method. In case 1 , OGTT was not performed because this patient already had a diagnosis of diabetes mellitus. In case 2, plasma GH levels were gradually suppressed to less than $1 \mathrm{ng} / \mathrm{ml}$ following OGTT (Fig. 2b). In cases 3 and 4, plasma GH levels remained less than $1 \mathrm{ng} / \mathrm{ml}$ following OGTT (Fig. 2b).

\section{GH response to bromocriptine}

Dopamine agonists stimulate GH secretion in normal subjects, but inhibit it in most cases of acromegalic patients. The effects of bromocriptine on GH levels were, therefore, examined in the ou patients. Changes in plasma GH levels were variable following bromocriptine, a dopamine agonist (Fig. 2c). In case 1, plasma GH levels remained unchanged. In cases 2 and 3, the plasma $\mathrm{GH}$ levels were elevated following administration of bromocriptine, whereas the plasma GH levels decreased after its administration in case 4 . 
(a)

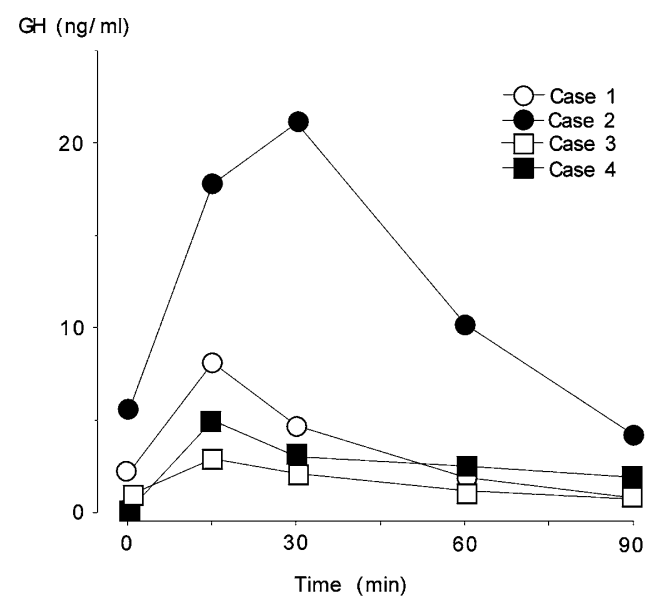

(c)

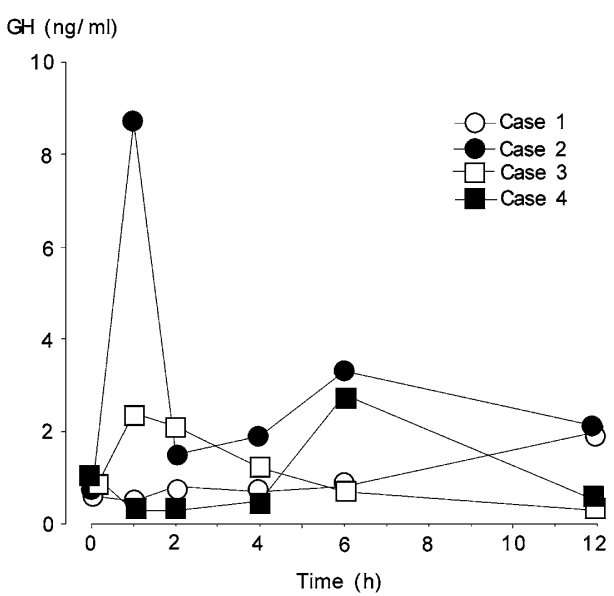

(b)

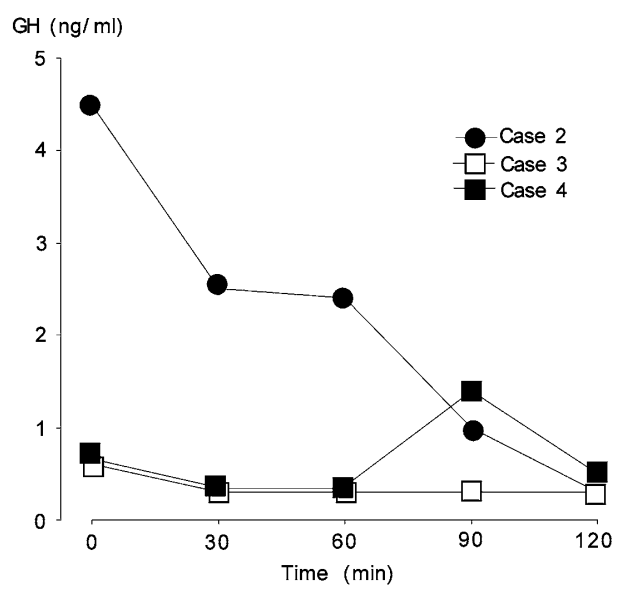

Fig. 2. Hormone loading test results. (a) TRH test (TRH $200 \mu \mathrm{g}$, intravenous bolus). (b) OGTT (75 g glucose, per os). (c) Bromocriptine (bromocriptine $2.5 \mathrm{mg}$, per os).

TABLE 2. Physical findings and roentgenograms

\begin{tabular}{|c|c|c|c|c|c|c|}
\hline \multirow{2}{*}{ Case } & \multirow{2}{*}{$\begin{array}{c}\mathrm{BMI} \\
\left(\mathrm{kg} / \mathrm{m}^{2}\right)\end{array}$} & \multicolumn{5}{|c|}{ Signs/Symptoms } \\
\hline & & Perspiration & Athropathy & Carpal tunnel & Snoring & Sleep apnea \\
\hline 1 & 33.2 & - & - & + & - & - \\
\hline 2 & 21.1 & - & - & - & + & - \\
\hline 3 & 24.6 & - & + & - & - & - \\
\hline 4 & 23.5 & + & - & - & - & - \\
\hline \multirow{2}{*}{ Case } & \multicolumn{4}{|c|}{ Roentgenograms } & & \\
\hline & Heel pad (mm) & Hand deformity & Submandibular angle & Basilar prognathism & & \\
\hline 1 & 22 & - & - & - & & \\
\hline 2 & 17 & - & - & - & & \\
\hline 3 & 21 & - & - & - & & \\
\hline 4 & 19 & - & - & - & & \\
\hline
\end{tabular}

BMI, body mass index; heel pad, heel pad thickness; hand deformity, cauliflower-like deformity in hand roentgenogram; submandibular angle, opening of submandibular angle in skull roentgenogram. 


\section{Discussion}

We present four patients with pre-clinical acromegaly. Pituitary tumors were demonstrated by magnetic resonance imaging in half the cases. In the cases where no pituitary tumor was evident, it is possible that the GH-producing tumor was too small to be detected by magnetic resonance imaging. Otherwise, although very rare, it is also possible that an ectopic GH-releasing hormone-producing tumor, stimulating GH and IGF-I secretion, could exist elsewhere. Basal GH levels were within normal levels $(<5 \mathrm{ng} / \mathrm{ml})$ in 3 of 4 cases, while IGF-I levels were elevated in all cases. Plasma GH levels were elevated in response to TRH in all cases, while an OGTT was not useful for the diagnosis, because of the low basal GH levels (less than $1 \mathrm{ng} / \mathrm{ml}$ ) in two cases or diabetes mellitus in one case. In response to a dopamine agonist, GH levels were increased in the two cases, while they remained unchanged or were decreased in the other two cases. In the four cases presented here, elevated plasma IGF-I levels and GH levels that responded to TRH infusion, suggested unregulated abnormal secretion of GH from the pituitary tumor (Diez et al. 2001). The patients, however, had minimal acromegaloid features, suggesting that the tumor secretes $\mathrm{GH}$ that is insufficient to cause typical clinical symptoms in acromegaly, so-called pre-clinical acromegaly. In cases of pre-clinical acromegaly, the TRH stimulation test might be a useful tool.

Pre-clinical Cushing's syndrome has been well recognized (Suda 2002). We present here four patients with pre-clinical acromegaly. Patients with acromegaly may develop the clinical symptoms gradually (Thorner et al. 1998). Most cases of pre-clinical acromegaly, therefore, might be in the very early stages of acromegaly development. Considering the complications of acromegaly such as hypertension, diabetes mellitus, and colon polyps, or the observation of a pituitary adenoma, appropriate testing is an important part of the decision process as to whether pre-clinical acromegaly should receive treatment, in order to possibly prevent the irreversible changes and complications of acromegaly.
The biochemical diagnostic criteria for acromegaly are still under debate. Recently, the following criteria were proposed by Trainer (2002): during an initial random GH and IGF-I test, if the $\mathrm{GH}$ is less than $0.3 \mu \mathrm{g} / \mathrm{l}$ and the IGF-I is normal, then acromegaly is excluded; but if either the GH is $0.3 \mu \mathrm{g} / 1$ or greater or serum IGF-I is above the age- and gender-related reference range, then the patient should proceed to have a 75-g OGTT and repeat IGF-I measurement. Failure of GH to suppress less than $0.3 \mu \mathrm{g} / \mathrm{l}$ during the OGTT and an elevated IGF-I is diagnostic of acromegaly; suppression of GH below this limit and a normal IGF-I excludes acromegaly, while the rare patient with GH suppression and an elevated IGF-I requires following. The revised GH criteria in combination with IGF-I would be useful for the diagnosis and follow-up of acromegaly, but may require additional diagnostic testing in order to diagnose pre-clinical acromegaly.

After glucose ingestion, the plasma GH level is suppressed in normal individuals. In acromegaly, the oral glucose ingestion may decrease partially, remain unchanged, or paradoxically increase the GH level (Thorner et al. 1998). The criterion for a normal GH response to OGTT is less than $1 \mathrm{mg} / \mathrm{l}$ using an RIA method (Beck et al. 1966; Cryer and Daughaday 1969). In case 1 in our study, an OGTT was not performed because the patient had diabetes mellitus. In case 2, plasma GH levels were gradually suppressed to less than $1 \mathrm{ng} / \mathrm{ml}$ following an OGTT. In cases 3 and 4, plasma GH levels remained suppressed below the normal limits. In most cases of pre-clinical acromegaly, basal GH levels are already lower than the criterion suggests. Therefore, with pre-clinical acromegaly, an OGTT is inadequate for the diagnosis.

Other provocative or inhibitory tests have been proposed for the diagnosis of acromegaly, including administration of TRH, LHRH, and dopamine agonists. These tests have paradoxical effects in acromegalic patients. GH levels are elevated by TRH and LHRH, in 70-80\% and 30\%, respectively, of acromegalic patients (Irie and Tsushima 1972; Hanew et al. 1980; Utsumi et al. 1992). Dopamine agonists stimulate GH secre- 
tion in normal individuals, but paradoxically inhibit it in 59-70\% of acromegalic patients (Liuzzi et al. 1974). However, in the two cases of our patients, GH levels were increased in response to bromocriptine. Because we feel that our subjects have pre-clinical acromegaly, then the administration of a dopamine agonist may fail to discriminate subjects with pre-clinical acromegaly from normal patients.

We feel that the TRH stimulation test is a good test for the diagnosis of pre-clinical acromegaly as GH values were elevated above those in normal individuals in all four of our cases, although TRH causes slight palpitation and nausea during the test. In acromegaly, the TRH-induced $\mathrm{GH}$ release is likely caused by the abnormal induction or sensitization of TRH receptors on pituitary somatotroph adenoma cells (Harvey 1990). Central aminergic or hypothalamic dysfunction also might cause the $\mathrm{GH}$ to rise in response to TRH. Elevated GH responses to TRH are, however, not specific for acromegaly because they have been documented in a variety of pathophysiological conditions such as depression and liver cirrhosis (Harvey 1990). Such conditions should be ruled out, before the TRH stimulation test as a tool for pre-clinical acromegaly. In all our cases, non-specific causes of elevated $\mathrm{GH}$ in response to TRH were ruled out prior to TRH testing.

Cases of acromegaly with normal GH levels have been reported (Mims and Bethune 1974; Brockmeier et al. 1992). Both GH and IGF-I act either independently or synergistically to induce skeletal and organ growth. In the cases of acromegaly with normal GH levels, it is probable that continuous, not pulsatile, GH secretion is enough to stimulate increased IGF-I levels, even within the normal ranges of the basal GH levels (Dimaraki et al. 2002; Kageyama et al. 2002). Alternatively, it is also possible that GH levels can normalize in the course of natural remission of acromegaly.

In summary, we report four patients with minimal acromegaloid features and elevated IGF-I levels, suggesting that GH levels are insufficient to cause the typical clinical symptoms of acromegaly, so-called pre-clinical acromegaly.
We suggest that the TRH stimulation test would be useful to examine the presence of pre-clinical acromegaly. If the TRH stimulation test is negative or equivocal, we recommend that the elevated IGF-I levels should be followed, along with periodic TRH testing, especially with the advancement of pre-clinical features. It is important to diagnose the early stages of acromegaly, in order to prevent progression to overt acromegaly including the irreversible changes and complications that accompany this debilitating disease.

\section{Acknowledgments}

This work was supported in part by Health and Labour Science Research Grants (Research on Measures for Intractable Diseases) from the Ministry of Health, Labour and Welfare of Japan, and by a grant to T.S. from the Ministry of Education, Science and Culture of Japan (No. 15590966).

\section{References}

Beck, P., Parker, M.L. \& Daughaday, W.H. (1966) Hypersecretion of growth hormone in response to glucose. J. Clin. Endocrinol. Metab., 26, 463-469.

Brockmeier, S.J., Buchfelder, M., Adams, E.F., Schott, W. \& Fahlbusch, R. (1992) Acromegaly with 'normal' serum growth hormone levels. Clinical features, diagnosis and results of transsphenoidal microsurgery. Horm. Metab. Res., 24, 392-400.

Cryer, P.E. \& Daughaday, W.H. (1969) Regulation of growth hormone secretion in acromegaly. J. Clin. Endocrinol. Metab., 29, 386-393.

Diez, J.J., Iglesias, P. \& Gomez-Pan, A. (2001) Growth hormone responses to oral glucose and intravenous thyrotropin-releasing hormone in acromegalic patients treated by slow-release lanreotide. J. Endocrinol. Invest., 24, 303-309.

Dimaraki, E.V., Jaffe, C.A., DeMott-Friberg, R., Chandler, W.F. \& Barkan, A.L. (2002) Acromegaly with apparently normal GH secretion: implications for diagnosis and followup. J. Clin. Endocrinol. Metab., 87, 3537-3542.

Giustina, A. \& Melmed, S. (2003) Acromegaly consensus: the next steps. J. Clin. Endocrinol. Metab., 88, 1913-1914.

Hanew, K., Kokubun, M., Sasaki, A., Mouri, T. \& Yoshinaga, K. (1980) The spectrum of pituitary growth hormone responses to pharmacological stimuli in acromegaly. J. Clin. Endocrinol. Metab., 51, 292-297.

Harvey, S. (1990) Thyrotrophin-releasing hormone: a growth hormone-releasing factor. J. Endocrinol., 125, 345-358.

Irie, M. \& Tsushima, T. (1972) Increase of serum growth hormone concentration following thyrotropin-releasing hormone injection in patients with acromegaly or gigantism. $J$. Clin. Endocrinol. Metab., 35, 97-100.

Kageyama, K., Nigawara, T., Kamata, Y., Takahashi, T., Anzai, J., Suzuki, S., Osamura, Y.R. \& Suda, T. (2002) A case of macroprolactinoma with subclinical growth hormone production. Endocrine J., 49, 41-47. 
Liuzzi, A., Chiodini, P.G., Botalla, L., Cremascoli, G., Muller, E.E. \& Silvestrini, F. (1974) Decreased plasma growth hormone $(\mathrm{GH})$ levels in acromegalics following $\mathrm{CB}$ 154(2-Br-alpha ergocryptine) administration. J. Clin. Endocrinol. Metab., 38, 910-912.

Mims, R.B. \& Bethune, J.E. (1974) Acromegaly with normal fasting growth hormone concentrations but abnormal growth hormone regulation. Ann. Intern. Med., 81, 781-784.

Stewart, P.M., Smith, S., Seth, J., Stewart, S.E., Cole, D. \& Edwards, C.R. (1989) Normal growth hormone response to the $75 \mathrm{~g}$ oral glucose tolerance test measured by immunoradiometric assay. Ann. Clin. Biochem., 26, 205-206.

Suda, T. (2002) Adrenal preclinical Cushing's syndrome. Japan Med. Associat. J., 45, 172-174.

Thorner, M.O., Vance, M.L., Laws, E.R., Horvath, E. \& Kovacs, K. (1998) The anterior pituitary. In: Williams' Textbook of Endocrinology, 9th ed., edited by J.D. Wilson,
D.W. Foster, H.M. Kronenberg \& P.R. Larsen. Philadelphia, W.B. Saunders Company, pp. 249-340.

Trainer, P.J. (2002) Editorial: acromegaly-consensus, what consensus? J. Clin. Endocrinol. Metab., 87, 3534-3536.

Turgut, G., Kaptanoglu, B., Turgut, S., Genc, O. \& Tekinturk, S. (2003) Influence of acute exercise on urinary protein, creatinine, insulin-like growth factor-I (IGF-I) and IGF binding protein-3 concentrations in children. Tohoku J. Exp. Med., 201, 165-170.

Utsumi, A., Hanew, K., Sugawara, A., Shimizu, Y., Murakami, O., Ikeda, H. \& Yoshinaga, K. (1992) Plasma growth hormone $(\mathrm{GH})$ responses to corticotropin-releasing hormone in patients with acromegaly-the effect of dexamethasone pretreatment and the comparison with $\mathrm{GH}$ responses to thyrotropin-releasing hormone, gonadotropin-releasing hormone and GH-releasing hormone. J. Endocrinol. Invest., 15, 167-171. 